\title{
BIOGRAFÍA HISTÓRICA Y ESTÉTICA SURREALISTA EN EL AULA: SIMÓN DEL DESIERTO DE LUIS BUÑUEL
}

\author{
Francisco SALVADOR VENTURA \\ Universidad de Granada
}

\section{Luis Buñuel y Simón del desierto.}

Un seguimiento atento a la obra cinematográfica del genial director aragonés Luis Buñuel permite identificar con claridad la entidad de una de las constantes definitorias de su cine, la repetida presencia de temas religiosos. La sorpresa es evidente si se tiene en cuenta que no ocultaba su condición de ateo. No obstante tal definición, casi desde el inicio de su carrera se individualiza con claridad esta componente fundamental en sus películas, algo que sin duda tiene que ver con la impronta que debió de dejar en su persona la formación jesuítica que recibió en su Aragón natal durante su infancia y adolescencia. Entre todos los filmes en los que la religión católica está presente, una relevancia especial ofrece su Simón del desierto, por razones de índole muy diferente, que van desde el retrato del ambiente religioso del paleocristianismo oriental, hasta las forzadas y humorísticas alusiones a las disputas teológicas de la época, pasando por la digresión noctámbula con la que se construye un final impactante.

La respuesta ante la lógica curiosidad acerca de la razón por la que vino a dirigir su atención sobre un ambiente y un personaje tan exóticos, temporal y espacialmente, la proporciona el propio director en dos lugares diferentes. Nos cuenta que la primera noticia que tuvo sobre Simeón el Estilita se remonta a la época de su estancia en la Residencia de Estudiantes madrileña, cuando un divertido García Lorca apareció con una jocosa anécdota relacionada con este santo varón oriental, extraída de un libro del autor medieval italiano Jacobo de Vorágine titulado La leyenda áurea. La risa del poeta granadino era provocada por la imagen escatológica del individuo situado sobre una columna, que, como consecuencia de la prolongada estancia y la escasa y frugal comida de su inquilino, ofrecía una visión que asemejaba a los restos conformados por la cera derretida en torno a una vela. Daba la impresión de que, como el propio Buñuel afirmó, "la mierda chorreaba por la columna como la cera gotea por los cirios" (Pérez Turrent y De la Colina, 1993: 137). 
Bien entrada la década de los años sesenta se puso a trabajar en este proyecto que venía acariciando desde tiempo atrás (Baxter, 1996: 311), para lo cual se trasladó a una biblioteca neoyorquina en la que reunió y manejó la escasa bibliografía existente sobre un personaje tan singular. El resultado de sus indagaciones fue la elaboración de un complejo y denso guión, previsto para convertirse en un largometraje, bruscamente reducido como consecuencia de problemas de índole financiero a un mediometraje de cuarenta y dos minutos de duración. Se puede comprobar con claridad cuando se visiona el film que su duración no es el resultado de una equilibrada construcción, sino que se observa un final sin duda abrupto por múltiples razones. Con desconcierto se asiste a la aparición de un avión en el desierto sirio de la época. Traslada a los dos principales personajes al infierno neoyorquino de una discoteca durante la celebración de los rituales desmedidos del sábado noche. A ello se refiere el propio Buñuel en un comentario al respecto en los siguientes términos:

Escribí un guión completo para una película de largo metraje. Por desgracia, Alatriste tropezó con algunos problemas financieros durante el rodaje, y hube de cortar la mitad de la película. Había previsto una escena bajo la nieve, peregrinaciones e incluso una visita (histórica) del emperador de Bizancio. Tuve que suprimir todas estas escenas, lo que explica el carácter un poco brusco del final (Sánchez Vidal 2004: 80).

La intención de Buñuel era finalizar el proyecto más adelante, cuando las adversas circunstancias económicas hubieran mejorado, pero el productor Gustavo Alatriste la presentó en la Mostra de Venecia de 1965 sin contar con su beneplácito. Ante el reconocimiento de los dos premios que le fueron concedidos, el director, disconforme con la iniciativa del productor, decidió dejarla tal como fue presentada y a la postre laureada, de manera que en adelante la película seguiría con esa factura inacabada. No fueron exitosas las gestiones de Alatriste para que algún otro director de renombre internacional tan probado como J. Huston, S. Kubrick, O. Welles o F. Fellini (por citar algunos) procedieran a completarla. Por esta razón hoy día podemos conocer esta película en el modo en el que fue repentina y provisionalmente terminada por razones en absoluto previstas en el proyecto inicial, fruto de circunstancias sobrevenidas, que contribuyeron a convertir esta última película de Buñuel en tierras mexicanas en una obra tan singular. 


\section{Simeón el Estilita y la potencialidad didáctica del film.}

Nadie se sentiría sorprendido si se hablara de la acentuada originalidad de la trayectoria de Luis Buñuel. Numerosos son los argumentos que se podrían esgrimir respecto de tal realidad. Uno de los más evidentes e ilustrativos lo proporciona precisamente este film, por la particularidad de que se trata de la única ocasión en la que una película de ficción desembarca en el ambiente del cristianismo oriental de la Antigüedad Tardía. Las industrias cinematográficas están vinculadas a Occidente y el contexto de un floreciente cristianismo oriental, en gran parte cegado por la temprana conquista islámica, no es un sujeto de tratamiento con suficiente atractivo, al menos en principio, para la nómina de espectadores acostumbrados a los grandes espectáculos antiguos y, en todo caso, con historias vinculadas al Antiguo Testamento y a la figura de Jesús de Nazaret.

Su excepcionalidad me llamó la atención desde que tuve ocasión de estudiarla con cierto detenimiento y me pareció por ello un material digno de un análisis más profundo tanto a nivel de investigación como en su posible dimensión docente. No es frecuente el uso de películas de ficción en el aula, donde, por el contrario, los documentales si son aprovechados para ilustrar determinados aspectos de las lecciones, por aquello del poder comunicativo de las imágenes. No obstante, me pareció oportuno su empleo en los diferentes niveles educativos en los que desempeño mi labor y la experiencia ha resultado a todas luces positiva. Los matices a reseñar en cada uno de ellos son distintos, pero en todos los casos son reveladores de la extraordinaria fuerza que esta película tiene y de la impresión que produce a quienes se sientan ante la pantalla. Los tres tipos de foros ante los que proyecté el film y procedí a un análisis compartido fueron: el Aula de Mayores, los estudiantes de Historia y los alumnos de un curso multidisciplinar sobre Cine e Historia.

\section{El Aula de Mayores}

Desde hace algunos años he tenido ocasión de impartir un curso sobre la imagen de la Historia en el Cine para los alumnos del Aula de Mayores. Se trata de un alumnado variopinto en su extracción social, su formación previa y el ambiente urbano 
en el que viven ${ }^{1}$. Pero todos ellos presentan el denominador común de tener una edad avanzada y de expresar un gran interés por el aprendizaje en algunos casos, por la actualización de información en otros y por mantener su inquietud por el conocimiento en otros más. Todo ello favorece que la actitud hacia los estímulos que se les presentan sea abiertamente favorable. La sorpresa es menor cuando se trata de películas relativamente conocidas o de otras cuyos esquemas discursivos están más próximos a los cánones habituales. Muchos de ellos conocen en mayor o menor medida a Luis Buñuel, pero prácticamente ninguno había visto esta película con anterioridad. Con esta proyección perseguía un doble objetivo; a saber, por un lado aspiraba a que conociesen un poco más sobre un mundo que presumía desconocían la mayor parte de ellos y, por otro, observar su reacción ante un tipo de hilazón de un discurso en principio poco amigo de una satisfacción fácil.

Tras una presentación sobre el director aragonés, procedíamos al visionado del film y, a su finalización, les preguntaba acerca de su primera impresión al respecto. Las respuestas fueron siempre de sorpresa, cuando no de estupefacción. No acababan de entender qué se pretendía con este film. Les habían llamado la atención aspectos particulares, como la ausencia de admiración por el milagro practicado por el eremita y las repetidas apariciones de un diablo con forma de mujer, pero su veredicto había sido negativo. Una explicación de algunas de las claves que se esconden en la elaboración del film y de los guiños humorísticos a la manera buñueliana esparcidos a lo largo del metraje favorecían una valoración menos reacia, pero siempre dentro de una actitud condescendiente de respeto hacia una obra con la que no llegaban a simpatizar. En cualquier caso, reconocían mayoritariamente que se trataba de la primera noticia de la existencia de un personaje tan extraordinario y se mostraban dispuestos a un segundo visionado con el que poder matizar su primera impresión.

\section{Los estudiantes de Historia}

Diferente es el tipo de auditorio que proporciona un grupo de alumnos de la Licenciatura de Historia, quienes parten de una postura inicial diferente, marcada quizá por un entusiasmo menos evidente, pero mediatizada por el hecho de que se trata de

\footnotetext{
${ }^{1}$ Con ello quiero aludir a condicionantes de índole puramente ambiental no directamente emparentadas con las anteriores. En mi caso el curso ha sido impartido en tres ciudades distintas, Granada, Guadix y Melilla, lo cual ha influido apreciablemente en las características del alumnado asistente.
} 
personas que han elegido esta disciplina como campo de formación personal. La predilección por la Historia como punto de partida está fuera de duda y el interés hacia los temas se da por descontado. El periodo de la Antigüedad Tardía es uno de los que históricamente ha sufrido una mayor desatención en las aulas universitarias, porque o bien solía situarse al final de los temarios, o bien por tratarse de una época de transición ofrecía menos atractivo que las etapas consideradas canónicas en la Historia. Y dentro del mundo tardoantiguo el cristianismo oriental quedaba también al margen, despertando atención en mayor medida su desarrollo en los territorios del Imperio Bizantino que sobrevivieron al empuje inicial del Islam. En este caso, la película de Buñuel les es presentada como un vehículo para aproximarse al abigarrado mundo del anacoretismo oriental. Como punto de partida, resulta de gran validez, porque el director aragonés se documentó ampliamente en una biblioteca neoyorquina dirigiéndose directamente a las fuentes originales, evitando el usual recurso de acudir a noticias indirectas. Las empleadas fueron las dos obras de referencia existentes hasta ese momento, que continúan siendo aún en la actualidad las mejores fuentes de información existentes acerca de la figura de Simeón el Estilita, porque en ellas se recogen todas las noticias que existen sobre el personaje ${ }^{2}$. Así pues, se puede plantear un acercamiento a su figura a través de la lectura directa de alguna de los textos en los que se informó para el film.

El modus operandi es similar al del caso anterior, comenzando por una breve presentación del filme, con la particularidad de incidir más en la figura del personaje histórico que en las correspondientes a la película, para, una vez finalizada la proyección, recabar su opinión antes de proceder al trabajo directo con las fuentes. Las reacciones son también de sorpresa, con la particularidad de que no existe una reacción negativa ante las singularidades discursivas del texto fílmico, sino una curiosidad que les sugiere el desconocimiento del tema y todas las variables terminológicas relacionadas con los conceptos teológicos citados, así como algunos recursos iconográficos. El riesgo recurrente en estos casos es la tentación comparativa de la película proyectada con los textos en los que se inspira. Resulta una reacción predecible, y hasta cierto punto comprensible, dentro del mundo de los historiadores. Pero se debe estar atento en este terreno y no olvidar que los resultados tienen que ser medidos con

\footnotetext{
${ }^{2}$ Estas obras son H. DELEHAYE, Les saints stylites, Subsidia Hagiographica 14, Société des Bollandistes, Bruxelles, 1923 y A. J. FESTUGIÈRE, Antioche païenne et chrétienne, Éditions de Boccard, Paris, 1959.
} 
criterios distintos, sin rechazar inmediatamente toda aquella obra que no interprete la fidedignidad en términos historiográficos.

\section{Los estudiantes de Cine e Historia}

El perfil de los matriculados en los cursos dedicados a estudiar las relaciones entre Cine e Historia es heterogéneo, puesto que en ellos se inscriben alumnos procedentes de licenciaturas muy variadas, amén de algunos profesionales y licenciados. Todos han elegido voluntariamente participar en estos cursos, puesto que no forman parte de ningún plan de estudios de enseñanzas regladas, si bien pueden con posterioridad convalidarse por créditos. El objetivo en este caso es reflexionar acerca de la importancia de la dimensión histórica en el medio cinematográfico y analizar las fórmulas empleadas para concretarla. Elemento fundamental en tal contexto es tener bien presente que se ha de desterrar la automática comparación con los datos históricos conocidos previamente, que, como ya se ha indicado, contaminan la actitud de quien se sienta ante una producción histórica. La detección y relación de los gazapos históricos deviene un test de erudición de quienes se presentan con una actitud que refuerza los egos de determinados espectadores. Es necesario partir de que un análisis de un film histórico se corresponde con algo más complejo que la aplicación de este test de autenticidad y de que una película ni es ni pretende ser un libro de historia. Un film es una creación, una obra de arte, de mayor o menor entidad, pero con el condicionante definitivo de que está sujeto a imperativos de muy diferente índole relacionados con el hecho de la ficción. Las claves discursivas, por tanto, aparecen marcadas por recursos visuales destinados a captar la atención de los espectadores o a provocarles sensaciones determinadas, contando además con un elenco de elementos en juego más amplio que el que proporciona únicamente la palabra escrita.

La reacción de los alumnos ante esta película sigue siendo de sorpresa, por las singularidades antes expuestas, sobre todo ante el inesperado y brusco final, pero la actitud es marcadamente receptiva hacia una explicación posterior ante tan curioso montaje. La explicación posterior de algunas de las claves, simbologías, libertades e improvisaciones de Buñuel suscitan preguntas y observaciones de quienes ya han asumido el punto de partida anteriormente señalado, que se viene subrayando desde el inicio de estos cursos: la realidad de un texto fílmico histórico obedece a claves más complejas que las de un discurso histórico al uso. 


\section{Luis Buñuel y la recreación surrealista de Simeón.}

La razón por la que el director aragonés se decidió a encarar este insólito proyecto de dedicar un film a la figura de Simeón el Estilita no fue tanto la confesada anécdota escatológica de su juventud cuanto la admiración que le provocaba este tipo de personajes, a quienes denominó "extraordinarios" (Pérez Turrent y De la Colina, 1993: 137). Herederos en alguna medida de movimientos filosóficos alternativos del mundo griego, los anacoretas orientales de la Antigüedad Tardía abandonaban la comodidad del mundo civilizado de la época para retirarse a inhóspitos lugares, donde se dedicaban a sus prácticas ascéticas orientadas a alcanzar mediante la oración y la penitencia la ansiada aproximación a Dios. De gran atractivo le resultaba esta forma de vida y, en especial, aquella que condujo al pionero Simeón a situarse sobre la superficie de una columna para conseguir el doble objetivo de aislarse físicamente del mundo, al tiempo que se emplazaba en un lugar más próximo a Dios, creando con ello un ejemplo imitado por muchos con posterioridad.

En modo alguno, el proyecto aspiraba a componer una traslación directa a imágenes de la vida del personaje, una biografía histórica que pudiese complacer a los historiadores. Un creador de las características y la talla de Buñuel no se resignaba a perder la libertad creativa de la que hizo gala a lo largo de toda su trayectoria. Ello no quiere decir que el guión y su traslación a la pantalla fueran fruto de una composición caprichosa y gratuita, sino que, como se ha indicado, sus fuentes de inspiración fueron las originales, las existentes acerca de la figura tratada. Para quedar con las manos más libres respecto de esta cuestión, el director se cura en salud afirmando que su objetivo no era realizar una película sobre el fundador del grupo de los estilitas, sino sobre uno cualquiera de ellos de nombre Simón (Sánchez Vidal, 1984: 283-284). Esta circunstancia le permite tener una cobertura ante los hipercríticos, con el objeto de abordar la singularidad de la figura de Simeón, para utilizarla como punto de partida en una serie de alusiones y reflexiones en torno a asuntos religiosos que trascendían y siempre habían sido objeto de sus preocupaciones personales, que, de forma resumida, se podrían situar como las relaciones entre el individuo y la religión, tan arraigadas en la tradición hispana (Salvador Ventura, 2006).

La fórmula con la que tales inquietudes son llevadas a la pantalla resulta del empleo de recursos comunes en la persona del director aragonés y que, sin duda, pueden 
ser calificados como surrealistas, por su aparente ausencia de relación directa con el relato que se está desarrollando. Quizá la más evidente de todas sea la de acudir a la frecuente aparición del demonio en escena. El maligno intenta en cuatro ocasiones, y con diferentes apariencias, acabar con la rigurosa penitencia del santo varón. En ninguna de las fuentes existentes se hace alusión a las tentaciones sufridas por Simeón, lo cual no es óbice para que resulte de gran utilidad para mostrar visualmente cuáles eran los peligros de desafección que le acechaban. El mejor ejemplo de los riesgos que se presentaban ante un anacoreta de la época debían estar relacionados con las tentaciones de la carne, razón por la que decide que el diablo tome como materialización el cuerpo femenino. Así la actriz que representa al diablo, Silvia Pinal, adopta diferentes aspectos para presentarse ante el santo, que van desde la imagen de una mujer común de la época, hasta la apariencia de una joven inocente que muestra sin recato sus encantos y la simulación del tipo iconográfico con el que en el paleocristianismo se representaba a Dios, el Buen Pastor.

Tema de preocupación reiterado también para Buñuel es el referente a la blasfemia, algo que tampoco tiene relación directa con la figura del santo sirio, y al que confiere un elevado protagonismo en la película. El demonio no es el único encargado de blasfemar, sino que un monje de la comunidad vecina al emplazamiento de la columna, Trifón, es el protagonista de una secuencia humorística con un acentuado sabor buñueliano. Un ardid de este monje pretende dejar en evidencia a Simeón y, tras la invocación a la divinidad para que aclarase el enredo, Trifón es poseído por el diablo y comienza a proferir una serie de blasfemias en las que condenaba conceptos canónicos claves dentro de las disputas teológicas cristianas tardoantiguas, que eran automáticamente contestadas en sentido contrario por el grupo de monjes que asistían escandalizados a la escena. El cruce de vivas y mueras compulsivos dio lugar a alguna confusión puntual como aquella en la que en un momento determinado el grupo llega a proferir un "Muera Jesucristo" rápidamente rectificado.

Con estos dos aspectos citados a título de ejemplo se podría argumentar que la película no tiene mucho que ver con lo que se considera una buena película histórica. Libertades anacrónicas fruto de las inquietudes personales del director abundarían en esa negativa consideración acerca de lo que sería una biografía histórica elaborada en un modo históricamente aceptable. Tal consideración sería, a mi juicio, de todo punto inadecuada e injusta, porque Buñuel ni es ni pretende ser un historiador, sino un director de cine. Y partiendo de tal realidad comienzan a invertirse unos valores que no hacen 
sino ensalzar la categoría fílmica e histórica de la película. Sobre la primera no hay dudas, como queda probado gracias a los éxitos cosechados por el film y el reconocimiento mundial que la figura del director aragonés ha suscitado desde hace años. Acerca de la histórica, no se puede dejar de lado la corrección de un modus operandi que se dirigió desde el primer momento a un contacto directo con las fuentes originales (Salvador Ventura, 2007), eliminando cualquier tipo de intromisión indirecta contaminante. Las abundantes digresiones que se permite el director a lo largo del film están en relación con problemáticas históricas y personales a propósito de la compleja relación entre el hombre y la religión católica a lo largo de los siglos, que tienen su reflejo en sus propias preocupaciones. Y, en último término, no se puede olvidar que se trata de la única película existente sobre el ambiente religioso oriental que ha sido elaborada en la historia del cine. Que el motivo de su tratamiento fueran los comentarios de un joven García Lorca en la Residencia de Estudiantes no pasa de ser una divertida anécdota, porque detrás de ello se esconden las inquietudes personales de un ateo preocupado por la religión católica y la curiosidad de una persona interesada por la conformación de esa religión. Todo ello no hace sino revivir al modo buñuelino una época apenas conocida en el mundo occidental, que puede ser presentada a la curiosa mirada de alumnos de diferente índole, dispuestos a conocer mejor la Historia y sorprendidos por un espectáculo tan singular. 


\section{BIBLIOGRAFÍA:}

BAXTER, John, Luis Buñuel. Una biografía, Barcelona, Paidós, 1996.

PÉREZ TURRENT, Tomás y DE LA COLINA, José Antonio, Buñuel por Buñuel, Madrid, Plot, 1993.

SALVADOR VENTURA, Francisco, "La imagen hispana de un icono cristiano: Simón del desierto por Luis Buñuel", en AA.VV., Les Cahiers du GRIMH. Image et pouvoir, Lyon, 2006, Grimh-LCE-Grimia, pp. 401-411.

, "Una imagen fílmica rigurosa de la Antigüedad Tardía: Simón del desierto de Luis Buñuel", Habis 38, 2007, pp. 341-356.

SÁNCHEZ VIDAL, Agustín, Luis Buñuel. Obra cinematográfica, Madrid, Ediciones JC, 1984.

Luis Buñuel, Madrid, Cátedra, 2004.

SANTAOLALLA, Isabel et alii (coords.), Buñuel, siglo XXI, Zaragoza, Inst. Fernando el Católico y Prensas Universitarias de Zaragoza, 2004. 